\title{
Nonparental Adults as Social Resources in the Transition to Adulthood
}

\author{
Esther S. Chang \\ Soka University of America \\ Ellen Greenberger, Chuansheng Chen, and Jutta Heckhausen \\ University of California, Irvine \\ Susan P. Farruggia \\ The University of Auckland \\ This short-term longitudinal study examined whether the social resources of important \\ nonparental adults (VIPs) perceived by youth during their senior year of high school had a \\ significant relation to their educational and socioemotional adjustment 1 year later. One month \\ before their high school graduation, a multiethnic sample of youths $(N=754)$ reported on their \\ grades, educational expectations, and selected psychosocial characteristics (i.e., depressed mood \\ and misconduct); the educational attainment and perceived psychosocial characteristics of an \\ important nonparental adult in their lives; and the educational plans and perceived psychosocial \\ characteristics of their close friends. Key measures were included in a mailed survey 1 year later. \\ VIP characteristics (particularly their educational attainment) were associated with post-high \\ school adjustment, even after controlling for previous level of youth adjustment and contribu- \\ tions from demographic and peer characteristics.
}

A solid body of research has shown that development during the adolescent years is influenced not only by parents and peers, but also by the nonparental adults who have become important in their lives (DuBois \& Karcher, 2005; Zimmerman, Bingenheimer, \& Notaro, 2002). These adults may be mentors who serve as role models (Allen, Eby, \& Lentz, 2006; Levinson, 1978), persons who serve as sources of support (Klaw \& Rhodes, 1995; Klaw, Rhodes, \&

Requests for reprints should be sent to Esther S. Chang, Soka University of America, 1 University Drive, Aliso Viejo, CA 92656. E-mail: echang@soka.edu 
Fitzgerald, 2003; Rhodes, Ebert, \& Fischer, 1992), or individuals who play a broad role that encompasses these and other functions and who occupy a status somewhere between that of parent and peer (see Beam, Chen, \& Greenberger, 2002, regarding “VIPs"). Relationships with mentors are sometimes formal as in Big Brother/Big Sister and other social programs, but these and other types of caring relationships also occur "naturally": that is, they arise as part of the normative experiences of growing up (Beam Gil-Rivas, Greenberger, \& Chen, 2002; Darling, Hamilton, Toyokawa, \& Matsuda, 2002; Rhodes et al., 1992). Approximately $45-85 \%$ of various adolescent samples in the United States report naturally occurring, important relationships with nonparental adults or mentors (Blyth, Hill, \& Thiel, 1982; Chen, Greenberger, Farruggia, Bush, \& Dong, 2003; Greenberger, Chen, \& Beam, 1998; Rhodes et al., 1992; Zimmerman et al., 2002), and a strong majority (73\%) of youth in a nationally representative sample reported that an adult other than their parents had made a positive difference in their lives since their early adolescent years (DuBois \& Silverthorn, 2005).

The potential benefits of naturally occurring mentors are widely cited. Important nonparental adults can help adolescents in challenging conditions to focus on a brighter future and overcome adversity (Garmezy, 1991; Klaw et al., 2003; Rhodes, Spencer, Keller, \& Liang, 2006; Werner \& Smith, 1977, 1982). Mentoring programs that aim to reproduce the psychosocial and instrumental benefits of naturally occurring mentor relationships have been found to be particularly successful among at-risk youth. A meta-analytic review of formal mentoring programs found that the largest estimated effect sizes were evident for programs directed toward youth experiencing socially deprived conditions (Dubois, Holloway, Valentine, \& Cooper, 2002). Yet, the advantages of important nonparental adults are not exclusive to at-risk youth. A nationally representative sample of young adults in the Add Health study who retrospectively indicated that they had an important nonfamilial adult during their adolescent years were more likely to have completed high school, attended college, and had employment for more than 10 hours a week (DuBois \& Silverthorn, 2005).

Nonetheless, the impact of formal mentors and VIPs has not always been for the better. Some evaluations of formal mentoring programs, for instance, have reported declines in academic achievement and worse outcomes for youth randomly assigned to mentoring compared with youth randomly assigned to a control group (DuBois et al., 2002). Furthermore, cross-sectional studies of community youth (Chen et al., 2003; Greenberger et al., 1998) found that although low levels of VIP misconduct and depression were related to low levels of adolescent misconduct and depression, high levels of VIP misconduct and depression were related to high levels of adolescent misconduct and depression.

After high school, youth typically begin to explore more seriously occupational possibilities that might lead to a career and often move out of the 
parental home. Although delinquency decreases, as youth's increased rights, responsibilities, and earning power enhance their feelings of maturity (Moffitt, Caspi, Harrington, \& Milne, 2002), the years between ages 18 and 25 are characterized by higher levels of depression than any period of life except old age (Kessler, Foster, Webster, \& House, 1992). The above review indicates that relationships with important nonparental adults are consequential to youth development and suggests that nonparental adults' social capital or lack thereof might impact youth's transition from high school to their next steps in life. Social capital encompasses aspects of the social environment that provide an individual with access to resources that make positive outcomes more likely (Coleman,1988). Relationships become social capital when they are used to expand or secure achievements (e.g., admission to educational programs, obtaining jobs, meeting new friends). Youth may prefer nonparental adults to either parents or peers as sources of social capital during the transition to adulthood because they provide a unique bridge to the adult social world. Adolescents get to choose their VIPs and are likely to select ones whose influence they welcome for the most part (Chen et al., 2003). A VIP may be able to provide information and connections that parents cannot offer, especially parents who are less socially advantaged (e.g., immigrant or ethnic minority status), and are less likely than parents to threaten youth's autonomy.

Previous research on natural mentors has relied on either cross-sectional designs or retrospective reports (see Klaw et al.'s 2003 study on African Americans for the only exception). To overcome this limitation, the present study sought to extend the cross-sectional findings of Greenberger et al. (1998) and Chen et al. (2003) by examining VIP characteristics as perceived by youth before the end of their senior year with youth outcomes measured 1 year later. We hypothesized that youth's perception of VIP social capital at the end of high school senior year would be associated with reports of their educational and socioemotional adjustment 1 year later, over and above any effects due to perceived peer social capital and after controlling for initial levels of adjustment. Youth's perceptions, although not always accurate, have been found to be as important in influencing behavior as actual behaviors or resources (Brown, Clasen, \& Eicher, 1986). Indicators of perceived social capital include adolescents' report of their VIP and peers' educational attainment and perceived well-being (i.e., levels of depression and engagement in misconduct). Outcomes that we view as indicating adjustment in the transitional year include educational expectations, school grades for those individuals enrolled in some form of postsecondary education, depressive symptomatology, and involvement in misconduct. High educational expectations would indicate social and economic ambitions. Good grades would reflect youth's investment in their education and training. Depressive symptomatology and misconduct would gauge adolescents' psychosocial adjustment or well-being. 


\section{METHOD}

A single cohort of high school seniors was recruited from four schools in the Los Angeles Unified School District. Two time points were used for the current study: Time 1 (T1) data were collected 1 month before high school graduation and Time 2 (T2) data were collected 1 year later. At T1, participants completed a 50-minute survey during a class period $(N=1,183)$. In each classroom, the names of two participants were randomly selected to receive US\$20 gift certificates to a local record store and all were entered into a school-wide drawing for two US\$100 gift certificates. Students who were minors needed written parental consent to participate in the study (refer to Chang, Chen, Greenberger, Dooley, \& Heckhausen, 2006, for details). One year later at T2, 754 (64\%) responded to a mailed follow-up survey accompanied by a prepaid return envelope and were compensated US $\$ 40$.

The longitudinal sample was comprised of Latino Americans $(29 \% ; n=217$, of which 140 were of Mexican ancestry), European Americans (23\%; $n=170)$, Asian Americans (Korean, Chinese, Vietnamese, and Filipino; $21 \%$; $n=159$ ), and African Americans $(11 \% ; n=85)$. The remaining participants were from multiethnic backgrounds or from other ethnic groups (e.g., Pakistani, Indian, Middle Eastern; $16 \% ; n=120)$. Overall, $57 \%(n=451)$ of participants were children of immigrants. The majority of participants reported that they lived with both biological parents (62\%), whereas $20 \%$ reported living with their mother only, $8 \%$ with their mother and stepfather, and 10\% reported living in a variety of other arrangements. The average level of parental educational attainment was a vocational or technical degree ( $M=3.2$ on a 5-point scale). Most participants were enrolled as part- or full-time students 1 year after high school (17\% and $78 \%$, respectively), and $4.5 \%$ had enrolled in postsecondary school but dropped out by the time of the follow-up study. A majority $(60 \% ; n=442)$ of the sample was employed; average hours employed was 28.4 hours per week $(S D=12.5)$.

Using T1 survey responses, we compared individuals who did not participate at the T2 follow-up with those who did. As is common in survey research, the sample of participants who completed surveys at both times contained a significantly higher percentage of females $(60 \%)$ than did the original sample; $43 \%, \chi^{2}(1, N=1,170)=31.67, p<.001$. The longitudinal sample also contained somewhat more Asian Americans, $\chi^{2}(1, N=1,183)=$ 9.78, $p<.01$, more European Americans, $\chi^{2}(1, N=1,183)=12.06, p=.001$, and fewer Latinos, $\chi^{2}(1, N=1,183)=15.86, p<.001$, than did the T1-only sample. The proportion of African Americans and "Others" did not differ across the two samples. Participants in the longitudinal sample had slightly better senior-year grades than the T1-only participants (.65 mean difference on a 7 -point scale), $t(1,175)=7.35, p<.001$, and also had parents with higher educational attainment (.23 mean difference), $t(1,077)=2.83, p<.01$. Although the two samples did not differ significantly in mean level of depressed mood at T1, the longitudinal sample reported slightly less 
involvement in misconduct at $\mathrm{T} 1$ (.08 mean difference on a 4-point scale), $t(1,773)=-2.66, p<.01$. In order to further evaluate the effects of sample attrition, homogeneity of covariance among all study variables at $\mathrm{T} 1$ for the longitudinal and the subsample that was not followed up was tested using a Box $M$ test. Results indicated that the relations among study variables were equal across these two groups (Box's $M=86.78, p>.05$ ).

\section{Measures}

At T1, participants provided demographic information (gender, age, ethnicity, generational status). Generational status was a three-level variable indicating the recency of the youth's family immigration $(1=$ parents and youth were not born in the United States, 2 =youth was born in the United States but parents were not, 3 = at least one parent was born in the United States). Participants also reported the educational attainment of their mother (stepmother) and father (stepfather) or resident guardian (e.g., foster parent), on a 5 -point scale $(1=$ ninth grade or less to $5=$ Master's or professional degree). The parent with the most education provided the basis for highest parental educational attainment. For the primary measures detailed below, Table 1 summarizes the number of items, response scale, Cronbach's $\alpha$, mean, and standard deviation and Table 2 displays their intercorrelations.

TABLE 1

Psychometric Properties of Study Measures

\begin{tabular}{|c|c|c|c|c|}
\hline & Number of Items & Cronbach's $\alpha$ & Response Scale & $M(S D)$ \\
\hline \multicolumn{5}{|l|}{ VIP social capital } \\
\hline Educational attainment & 1 & - & $1-4$ & $2.98(1.12)$ \\
\hline Misconduct & 10 & .77 & $0-1$ & $0.10(.17)$ \\
\hline Depressed mood & 3 & .69 & $0-1$ & $0.21(.31)$ \\
\hline \multicolumn{5}{|l|}{ Peer social capital } \\
\hline Educational plans & 3 & .52 & $1-3$ & $2.47(.50)$ \\
\hline Misconduct & 10 & .87 & $0-1$ & $0.25(.28)$ \\
\hline Depressed mood & 3 & .73 & $0-1$ & $0.35(.37)$ \\
\hline \multicolumn{5}{|l|}{ T1 youth outcomes } \\
\hline Educational expectations & 1 & - & $1-4$ & $3.14(.74)$ \\
\hline Grades & 1 & - & $1-7$ & $4.93(1.49)$ \\
\hline Misconduct & 16 & .88 & $1-4$ & $1.40(.45)$ \\
\hline Depressed mood & 20 & .89 & $1-4$ & $1.99(.54)$ \\
\hline \multicolumn{5}{|l|}{ T2 youth outcomes } \\
\hline Educational expectations & 1 & - & $1-4$ & $3.15(.77)$ \\
\hline Grades & 1 & - & $1-7$ & $4.98(1.35)$ \\
\hline Misconduct & 16 & .81 & $1-4$ & $1.30(.34)$ \\
\hline Depressed mood & 20 & .89 & $1-4$ & $1.87(.52)$ \\
\hline
\end{tabular}




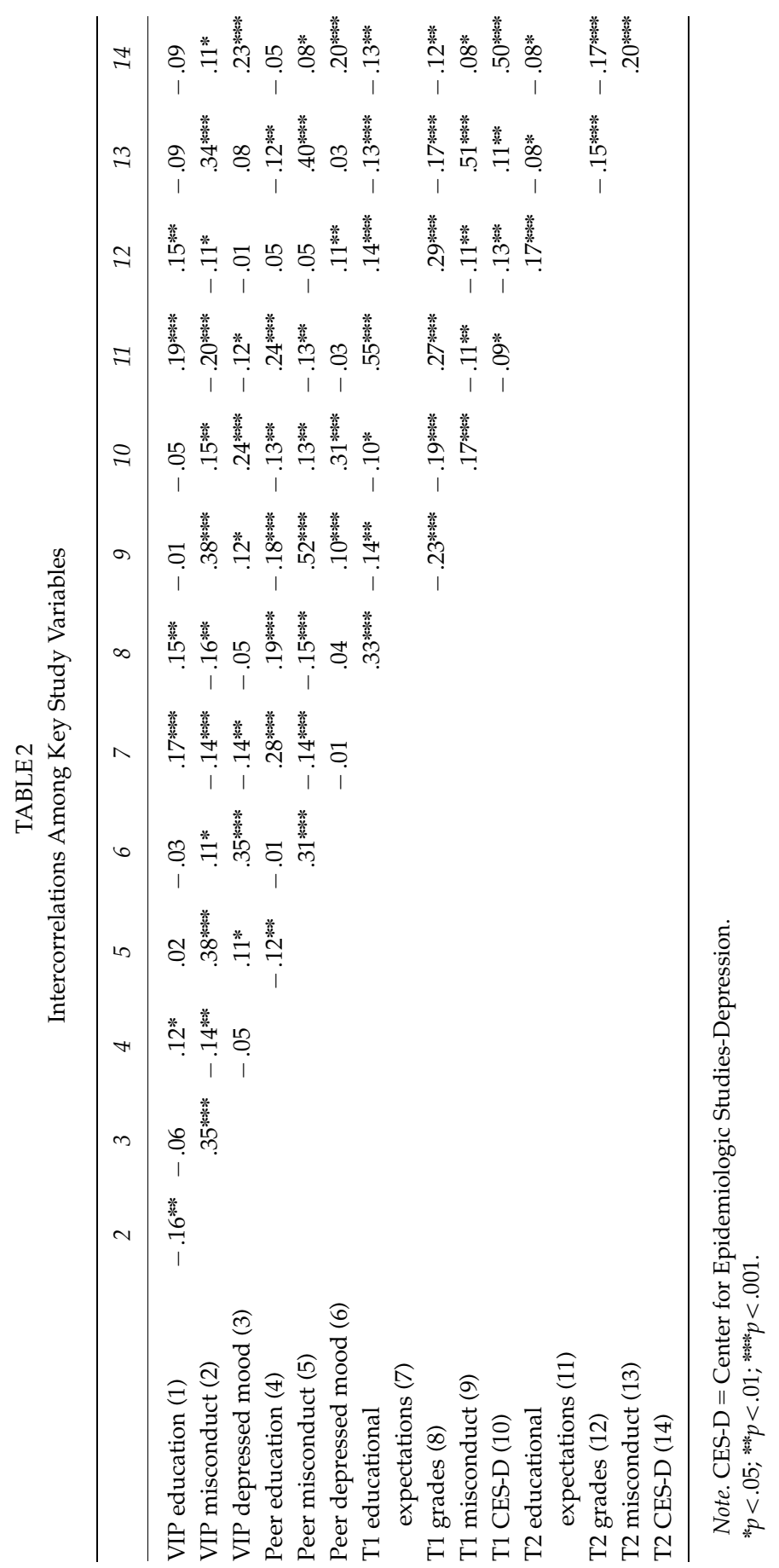


VIP characteristics and social capital. At T1, participants were asked whether they had an "important adult" (i.e., someone who was 21 years of age or over) in their lives other than their parents: "someone you feel you can count on, who will be there for you." Participants reported the level of importance of the "important adult" on a 3-point scale $(1=$ important, $3=$ truly key $)$, the person's gender $(0=$ male, $1=$ female $)$, age, and the type of relationship they shared. The latter was originally coded into 17 categories (e.g., aunt, coach), from which a dichotomous variable indicating kinship with the VIP also was coded $(0=n o n k i n, 1=k i n)$. Subtracting the participants' age from the age at which youth reported first meeting their VIP, the length of relationship was estimated.

Three measures of VIP social capital were assessed at T1. VIP educational attainment was measured by 1 item on a 4 -point scale $(1=$ ninth grade or less; $4=4$-year college or more). VIP misconduct was indicated by averaging participant responses to 10 items regarding whether $(0=n o ; 1=y e s)$ their VIP had engaged in various acts of misconduct during the past 6 months, such as theft, substance abuse, and physical aggression (Farruggia, Greenberger, Chen, \& Heckhausen, 2006). This scale was based on a subset of items from the youth misconduct scale described below. VIP depressed mood was assessed by averaging 3 items selected from the Center for Epidemiologic Studies-Depression (CES-D; Radloff, 1977) scale based on behaviors that youth can reasonably observe or perceive in others (e.g., Beam et al., 2002). Participants were asked to report whether $(0=n o, 1=$ yes $)$ their VIP had "acted depressed" and had "looked or said he/she was sad" during the past 6 months.

Peer social capital. A measure of peers' educational plans for their first posthigh school year was obtained by asking participants to identify up to three senior-year friends with whom they spent the most time in the past 3 months and answered the question, "Is this person going to go to college?" $(1=n o ; 2=2$-year college; $3=4$-year college) for each person. Answers to this question were averaged across all peers for whom the participant reported. Peer misconduct was assessed by calculating the mean response to the same 10 items that assessed VIP misconduct. In this case, participants indicated $(1=$ yes; $0=n o)$ whether "one or more of your friends" had engaged in various types of illegal or antisocial behavior (i.e., "stolen money or property," "drank alcohol frequently") in the last 6 months. Peers' depressed mood was ascertained by averaging responses to the same 3 items that were used to assess VIP's mood, but asking participants to refer to "one or more of your friends." Both measures of perceived peer misconduct and depressed mood were used in prior studies (e.g., Beam et al., 2002). Correlations among VIP and peer social capital indicators were negligible to moderate in size ( $r$ s ranged from - .02 to .38 ; see Table 2 ).

Youth adjustment. All indicators of youth's adjustment were assessed at both time points. Educational adjustment was measured by 2 items, one 
reflecting educational expectations, or the highest level of education participants realistically expected to complete, on a 4-point scale $(1=$ high school; $4=$ graduate school) and the other item reflecting school grades on a 7 -point scale $\left(1=\right.$ mostly $D^{\prime}$ s and $F^{\prime}$ s; $7=$ mostly $A^{\prime}$ s $)$. Grades were collected at T2 only for those who were students enrolled in any type of postsecondary education ( $n=687 ; 91 \%$ of the longitudinal sample). Socioemotional adjustment was indicated by measures of misconduct and depressed mood at both time points. Misconduct was indicated by the average response to a 16item scale adapted from Chen, Greenberger, Lester, Dong, \& Guo (1998) and consisting of items regarding frequency of physical aggression, other forms of antisocial behavior, and substance use. Participants responded about their behavior during the past year on a 4 -point scale $(1=$ never, $2=$ once or twice, $3=3-4$ times, $4=$ more often). Depressed mood during the past year was assessed by averaging responses to the 20-item CES-D scale (Radloff, 1977) on a 4 -point scale $(1=$ rarely or none of the time; $4=$ most or all of the time $)$.

\section{RESULTS}

\section{Youth With a VIP}

A majority $(60 \% ; n=450)$ of participants reported that they had a VIP in their lives during their high school senior year. Among those youth, a majority (58\%) reported that their VIP was kin related: specifically an older sibling (22\%), aunt/uncle (19\%), grandparent (9\%), or older cousin (7\%). Youth who identified a nonkin VIP identified an older friend/partner (15\%), school personnel (e.g., teacher, counselor, or coach; $12 \%$ ), or pastor, friend's parent, etc. $(14 \%)$. These results are similar to previous research on natural mentors in urban community samples (Chen et al., 2003; Zimmerman et al., 2002). Kinship with VIP did not differ by youth's gender or generational status but did differ by ethnicity, $\chi^{2}(4,441)=12.01, p<.05$. Proportionately more European American youth identified a nonkin VIP (55\%) whereas in all other ethnic groups proportionately more youth identified a kin VIP, ranging from $56 \%$ among Asian Americans to 67\% among African Americans. On average, youth had known their kin VIP since they were 1.2 years old $(S D=3.2$ years) whereas youth met their nonkin VIP when they were 13.7 years old $(S D=4.4$ years). Frequency of contact with a VIP did not differ by kinship, $t(441)=.99$, $p>.05$. The longitudinal sample and the sample that did not participate at the 1-year follow up did not differ with respect to whether the VIP was kin or nonkin, $\chi^{2}(1, N=644)=.19, p>.05$. Approximately half of the sample of youth with a VIP had a VIP who attained a 4-year college degree or higher $(51 \% ; n=228) ; 22 \%$ had some college $(n=98), 13 \%$ had attained a high school degree only $(n=59)$, and $14 \%$ had not finished high school $(n=65)$.

Independent samples $t$-tests comparing youth who had a VIP before the transition from high school with those who did not indicated that seniors 
with a VIP reported higher grades (mean difference $=.32$ ), $t(749)=3.00$, $p<.01$, and less misconduct (mean difference $=-.08$ ), $t(544)=-2.30$, $p<.05$, but did not differ with respect to educational expectations and depressed mood. The two groups of seniors did not differ in highest level of parents' educational attainment or perceptions of peer social capital (i.e., college plans, misconduct, and depressed mood) and the proportion of youth with a VIP did not differ across ethnic groups.

\section{Youth Adjustment Before and After High School Graduation}

A series of repeated measures analyses of variance comparing T1 and T2 responses showed significant mean-level declines in youth outcomes. Educational expectations decreased slightly (.06 mean difference), $F(1,750)=6.03, p<.05$, as did depressive symptomatology (.11 mean difference), $F(1,725)=29.52, p<.001$, and misconduct (.15 mean difference), $F(1,743)=104.46, p<.001$, in the year since high school graduation. Because grades achieved during high school are not equivalent to grades achieved in college (i.e., grading practices and course difficulty are likely to differ), grade comparisons were not examined. Results of multivariate analyses reported below should be interpreted within the context of the mean-level declines during the transition year.

\section{Multivariate Analyses}

To test whether VIP characteristics had distinctive associations with youthreported outcomes 1 year later, hierarchical linear regression models were constructed in the same design for each of the four transition outcomes. Baseline levels of the respective youth outcome and social demographic factors were entered in Step 1, peer characteristics in Step 2, and VIP characteristics in Step 3. Because kin and nonkin VIP have different functions and roles as well as different lengths of relationships with youth (Beam et al., 2002; DuBois \& Silverhorn, 2005), additional steps tested whether any unique contributions of VIP characteristics would remain after considering the potential confounds of kinship and length of youth-VIP relationship on Step 4. Finally, interaction terms were entered individually on Step 5, testing the interaction between kinship and length of relationship with the VIP as well as possible moderating effects of kinship or relationship duration on the association between any significant VIP factors and T2 outcomes. Interactions were tested following procedures recommended by Aiken and West (1991), including the centering of all predictor variables.

Educational expectations. Table 3 summarizes results from regressing youth's educational expectations at T2 on baseline educational expectations, gender $(1=$ female; $0=$ male $)$, highest level of parental educational 
TABLE 3

Hierarchical Regression Analyses Predicting Educational Expectations 1 Year After High School

\begin{tabular}{|c|c|c|c|c|c|c|c|c|}
\hline & \multicolumn{2}{|l|}{ Step 1} & \multicolumn{2}{|l|}{ Step 2} & \multicolumn{2}{|l|}{ Step 3} & \multicolumn{2}{|l|}{ Step 4} \\
\hline & $B(S E)$ & $\beta$ & $B(S E)$ & $\beta$ & $B(S E)$ & $\beta$ & $B(S E)$ & $\beta$ \\
\hline $\begin{array}{l}\mathrm{T} 1 \text { educational } \\
\text { expectations }\end{array}$ & $.59(.05)^{* * * *}$ & .53 & $.55(.05)^{* * * * *}$ & .50 & $.53(.05)^{* * * * *}$ & .48 & $.51(.05)^{* * * * * k}$ & .47 \\
\hline Gender & $.01(.07)$ & .01 & $-.02(.07)$ & -.02 & $-.02(.07)$ & -.01 & $-.03(.07)$ & -.02 \\
\hline Parental education & $.05(.03)$ & .08 & $.05(.03)$ & .08 & .04 (.03) & .06 & .03 (.03) & .05 \\
\hline African American & $.04(.12)$ & .02 & $.05(.12)$ & .02 & .04 (.12) & .02 & $.01(.12)$ & .00 \\
\hline Latino American & $.04(.12)$ & .03 & $.06(.12)$ & .03 & $.05(.12)$ & .03 & $-.00(.12)$ & -.00 \\
\hline Asian American & $.07(.12)$ & .04 & $.03(.12)$ & .02 & $-.02(.12)$ & -.01 & $-.05(.12)$ & -.03 \\
\hline Other ethnic groups & $.12(.10)$ & .06 & . $12(.10)$ & .06 & 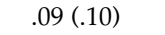 & .05 & .06 (.10) & .03 \\
\hline Generational status & $.02(.06)$ & .02 & $.02(.06)$ & .02 & $.01(.06)$ & .01 & $.01(.06)$ & .01 \\
\hline $\mathrm{T} 1$ peer education & & & $.16(.07)^{*}$ & .10 & $.14(.07)^{*}$ & .09 & $.14(.07)$ & .09 \\
\hline $\mathrm{T} 1$ peer misconduct & & & $-.17(.14)$ & -.06 & $-.14(.15)$ & -.05 & $-.15(.15)$ & -.05 \\
\hline $\mathrm{T} 1$ peer depressed mood & & & $-.00(.10)$ & -.00 & $.02(.10)$ & .01 & $.03(.10)$ & .01 \\
\hline T1 VIP education & & & & & $.08(.03)^{*}$ & .12 & $.09(.03)^{* * * *}$ & .13 \\
\hline T1 VIP misconduct & & & & & $-.18(.24)$ & -.04 & $-.18(.23)$ & -.04 \\
\hline T1 VIP depressed mood & & & & & $-.03(.12)$ & -.01 & $-.05(.12)$ & -.02 \\
\hline Relationship length & & & & & & & $.00(.01)$ & .04 \\
\hline VIP is kin-related & & & & & & & $.09(.13)$ & .06 \\
\hline$\Delta R^{2}$ & & & .014 & & $.016^{*}$ & & .008 & \\
\hline$R^{2}$ & $.298^{* * * * *}$ & & $.312^{* * * * *}$ & & $.329^{* * * * *}$ & & $.337^{* * * *}$ & \\
\hline $\operatorname{Adj} . R^{2}$ & $.282^{* * * * *}$ & & $.291^{* * * *}$ & & $.302 * * * *$ & & $.306^{* * * *}$ & \\
\hline
\end{tabular}

Note. All predictors were centered and $n=363$.

$* p<.05 ; * * p<.01 ; * * * * p<.001$

attainment, four ethnic background dummy variables (i.e., African American, Latino American, Asian American, and Other ethnic groups) that used European Americans as the reference group, and generational status in Step 1; T1 perceptions of peers' educational plans, misconduct, and depressed mood in Step 2; T1 perceptions of VIP educational attainment, misconduct, and depressed mood in Step 3; and finally, kinship with VIP $(\mathrm{kin}=1$; non kin $=0)$ and length of VIP-youth relationship in Step 4. The complete model (see Table 3, Step 4) accounted for $31 \%$ of the variance in educational expectations, $F(16,346)=11.00, p<.001$. Variables in Step 1 explained significant variance (28\%), most of it contributed by the previous year's educational expectations. (Youth's educational expectations were stable during the 1-year period, as indicated in Table 2.) Although the set of peer characteristics in Step 2 did not explain significant additional variance, T1 peers' educational plans were significantly and positively related to 
youth's educational expectations in the transition year. As hypothesized, the set of VIP characteristics in Step 3 explained significant additional variance, and VIP educational attainment predicted T2 educational expectations uniquely and positively. Kinship and length of relationship between youth and VIP did not explain significant additional variance in T2 educational expectations, and the significance of VIP educational attainment remained positive when these aspects of the relationship were controlled. Three post hoc interaction terms were tested individually in Step 5 (Kinship $\times$ Length; Kinship $\times$ VIP Education; Length $\times$ VIP Education). Only the interaction between kin relationship and VIP's educational attainment (not reported in table) was a significant predictor of T2 educational expectations, $b=-.20$ $(S E=.07) ; \beta=-.14, p<.01$. Post hoc probing (Holmbeck, 2002) indicated that the interaction reflected differences in the simple slopes between the nonkin regression line $(b=.22, p<.001)$ and the kin regression line $(b=.09$, $p<.05)$. Figure 1 displays the graphing of the interaction, which shows that VIP's educational attainment was associated positively with youth's educational expectations at T2 for both groups, but more strongly for youth who had a nonkin VIP.

School grades. For youth who entered postsecondary education after high school, self-reported postsecondary school grades were regressed onto the same set of predictors in the same four-step design described above. The only difference was in using $\mathrm{T} 1 \mathrm{high}$ school grades as a baseline measure. As detailed in Table 4, background variables and peer social capital explained $7 \%$ of the variance in postsecondary school grades. The model with the addition of VIP social capital (see Step 3) accounted for 9\% of the variance in postsecondary school grades whereas the full model with the addition of

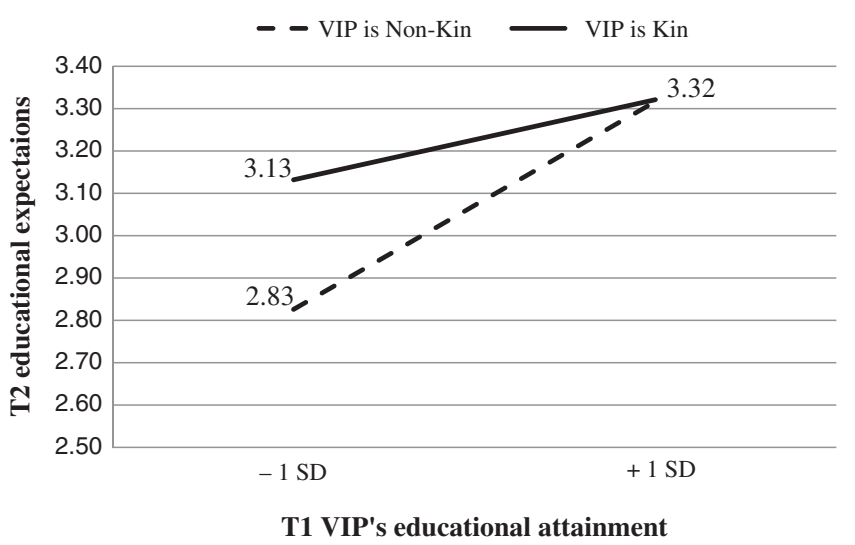

FIGURE 1 Interaction between VIP's educational attainment and kinship on T2 youth's educational expectations. 
TABLE 4

Hierarchical Regression Analyses Predicting School Grades 1 Year After High School

\begin{tabular}{|c|c|c|c|c|c|c|c|c|}
\hline & \multicolumn{2}{|l|}{ Step 1} & \multicolumn{2}{|l|}{ Step 2} & \multicolumn{2}{|l|}{ Step 3} & \multicolumn{2}{|l|}{ Step 4} \\
\hline & $B(S E)$ & $\beta$ & $B(S E)$ & $\beta$ & $B(S E)$ & $\beta$ & $B(S E)$ & $\beta$ \\
\hline T1 school grades & $.21(.06)^{* * * * *}$ & .21 & $.20(.06)^{* * * * *}$ & .21 & $.20(.06)^{* * *}$ & .20 & $.19(.06)^{* * *}$ & .20 \\
\hline Gender & $.39(.15)^{*}$ & .14 & $.36(.16)^{*}$ & .13 & $.34(.16)^{*}$ & .12 & $.35(.16)^{*}$ & .13 \\
\hline Parental education & $-.03(.07)$ & -.03 & $-.02(.07)$ & -.02 & $-.05(.07)$ & -.05 & $-.05(.07)$ & -.05 \\
\hline African American & $-.62(.26)^{*}$ & -.14 & $-.65(.27)^{*}$ & -.15 & $-.72(.26)^{* *}$ & -.17 & $-.71(.27)^{* * *}$ & -.17 \\
\hline Latino American & $-.48(.25)$ & -.15 & $-.48(.25)$ & -.15 & $-.49(.25)^{*}$ & -.16 & $-.48(.25)$ & -.15 \\
\hline Asian American & $-.32(.25)$ & -.11 & $-.35(.25)$ & -.11 & $-.46(.25)$ & -.15 & $-.45(.25)$ & -.15 \\
\hline Other ethnic groups & $-.35(.22)$ & -.10 & $-.38(.22)$ & -.11 & $-.43(.22)$ & -.13 & $-.42(.22)$ & -.13 \\
\hline Generational status & $.02(.12)$ & .02 & $.03(.12)$ & .02 & $.03(.12)$ & .02 & $.03(.12)$ & .02 \\
\hline $\mathrm{T} 1$ peer education & & & $-.05(.16)$ & -.02 & $-.08(.16)$ & -.03 & $-.08(.16)$ & -.03 \\
\hline $\mathrm{T} 1$ peer misconduct & & & $-.29(.30)$ & -.06 & $-.22(.32)$ & -.05 & $-.23(.32)$ & -.05 \\
\hline $\begin{array}{l}\text { T1 peer depressed } \\
\text { mood }\end{array}$ & & & $.26(.21)$ & .07 & $.27(.22)$ & .07 & $.27(.22)$ & .07 \\
\hline T1 VIP education & & & & & $.19(.07)^{* * *}$ & .15 & $.19(.07)^{* * * *}$ & .15 \\
\hline T1 VIP misconduct & & & & & $-.53(.52)$ & -.06 & $-.53(.52)$ & -.07 \\
\hline $\begin{array}{l}\text { T1 VIP depressed } \\
\text { mood }\end{array}$ & & & & & $.15(.27)$ & .04 & $.15(.27)$ & .04 \\
\hline Relationship length & & & & & & & $.00(.02)$ & -.01 \\
\hline VIP is kin-related & & & & & & & $.00(.27)$ & .00 \\
\hline$\Delta R^{2}$ & & & .005 & & $.027^{*}$ & & .000 & \\
\hline$R^{2}$ & $.094^{* * * * *}$ & & $.099^{* * * * *}$ & & $.127^{* * * *}$ & & $.127^{* * * *}$ & \\
\hline $\operatorname{Adj} . R^{2}$ & $.071^{* * * * *}$ & & $.067^{* * *}$ & & $.087 * * *$ & & $.081 * * *$ & \\
\hline
\end{tabular}

Note. All predictors were centered and $n=323$.

$* p<.05 ; * * *<<.01 ; * * * * k<.001$.

main effects of length and kinship (Step 4) did not account for any additional variance. High school grades were significantly and positively related to postsecondary school grades. Being male was also associated with significantly lower grades than being female, and African American youth had significantly lower postsecondary school grades than did European American youth. The addition of peer social capital in Step 2 did not explain significant additional variance in postsecondary school grades whereas the addition of VIP social capital in Step 3 did. High school seniors' VIP's educational attainment was positively related to youths' postsecondary school grades, an association that remained significant even after kinship and length of relationship were taken into account.

Misconduct. Youth-reported misconduct at T2 was regressed in the four-step design as previously described; results are reported in Table 5. 
TABLE 5

Hierarchical Regression Analyses Predicting Misconduct 1 Year After High School

\begin{tabular}{|c|c|c|c|c|c|c|c|c|}
\hline & \multicolumn{2}{|l|}{ Step 1} & \multicolumn{2}{|l|}{ Step 2} & \multicolumn{2}{|l|}{ Step 3} & \multicolumn{2}{|l|}{ Step 4} \\
\hline & $B(S E)$ & $\beta$ & $B(S E)$ & $\beta$ & $B(S E)$ & $\beta$ & $B(S E)$ & $\beta$ \\
\hline $\mathrm{T} 1$ misconduct & $.50(.04)^{* * * * *}$ & .58 & $.47(.04)^{* * * * *}$ & .55 & $.46(.05)^{* * * *}$ & .53 & $.46(.05)^{* * * k * k}$ & * .54 \\
\hline Gender & $-.02(.03)$ & -.04 & $-.02(.03)$ & -.02 & $-.01(.03)$ & -.02 & $-.01(.03)$ & -.02 \\
\hline Parental education & $-.00(.01)$ & -.01 & $-.00(.01)$ & -.00 & $.01(.01)$ & .02 & $.01(.01)$ & .02 \\
\hline African American & $-.11(.04)^{*}$ & -.11 & $-.11(.05)^{*}$ & -.11 & $-.10(.04)^{*}$ & -.10 & $-.10(.05)^{*}$ & -.10 \\
\hline Latino American & $-.11(.04)^{*}$ & -.16 & $-.12(.04)^{* * *}$ & -.16 & $-.12(.04)^{*}$ & -.16 & $-.12(.04)^{*}$ & -.16 \\
\hline Asian American & $-.08(.04)$ & -.12 & $-.07(.04)$ & -.10 & $-.05(.04)$ & -.07 & $-.05(.04)$ & -.07 \\
\hline Other ethnic groups & $-.00(.04)$ & .00 & $.00(.04)$ & .00 & $.01(.04)$ & .02 & $.01(.04)$ & .02 \\
\hline Generational status & $.02(.02)$ & .04 & $.01(.02)$ & .04 & $.02(.02)$ & .04 & $.02(.02)$ & .05 \\
\hline $\mathrm{T} 1$ peer education & & & $-.04(.03)$ & -.06 & $-.03(.03)$ & -.04 & $-.03(.03)$ & -.04 \\
\hline $\mathrm{T} 1$ peer misconduct & & & $.06(.06)$ & .06 & $.06(.06)$ & .05 & $.06(.06)$ & .05 \\
\hline $\begin{array}{l}\text { T1 peer depressed } \\
\text { mood }\end{array}$ & & & $-.02(.04)$ & -.03 & $-.02(.04)$ & -.03 & $-.02(.04)$ & -.03 \\
\hline T1 VIP education & & & & & $-.03(.01)^{* *}$ & -.12 & $-.04(.01)^{* * *}$ & -.13 \\
\hline T1 VIP misconduct & & & & & $.10(.10)$ & .05 & $.10(.10)$ & .05 \\
\hline $\begin{array}{l}\text { T1 VIP depressed } \\
\text { mood }\end{array}$ & & & & & $-.04(.05)$ & -.04 & $-.04(.05)$ & -.04 \\
\hline Relationship length & & & & & & & $-.00(.00)$ & -.03 \\
\hline VIP is kin-related & & & & & & & $.02(.05)$ & .03 \\
\hline$\Delta R^{2}$ & & & .005 & & $.018^{*}$ & & .000 & \\
\hline$R^{2}$ & $.416^{* * * *}$ & & $.422 * * *$ & & $.440 * * *$ & & $.440 * * *$ & \\
\hline Adj. $R^{2}$ & $.403^{\text {***** }}$ & & $.404^{* * * *}$ & & $.417^{* * * *}$ & & $.414^{* * * * *}$ & \\
\hline
\end{tabular}

Note. All predictors were centered and $n=361$.

$* p<.05 ; * * p<.01 ; * * * p<.001$.

Background variables and peer social capital explained $40 \%$ of the variance in misconduct 1 year after high school. The model with the addition of VIP social capital (see Step 3) accounted for $42 \%$ of the variance in T2 misconduct but the addition of Step 4 (main effects of length and kinship) did not account for any additional variance; $F(16,344)=16.88, p<.001$. Previous-year misconduct was the largest contributor, as expected in light of the stability of misconduct over this period (see Table 2). Two ethnic dummy variables also were significant: Latino American and African American youth reported significantly lower levels of misconduct than did European American youth 1 year after high school. The addition of peer characteristics in Step 2 did not explain significant additional variance whereas the addition of VIP characteristics in Step 3 contributed significant additional variance in accounting for T2 misconduct. T1 VIP educational attainment was a significant predictor of youth adjustment during the transition year. High 
TABLE 6

Hierarchical Regression Analyses Predicting Depressive Symptoms 1 Year After High School

\begin{tabular}{|c|c|c|c|c|c|c|c|c|}
\hline & \multicolumn{2}{|l|}{ Step 1} & \multicolumn{2}{|l|}{ Step 2} & \multicolumn{2}{|l|}{ Step 3} & \multicolumn{2}{|l|}{ Step 4} \\
\hline & $B(S E)$ & $\beta$ & $B(S E)$ & $\beta$ & $B(S E)$ & $\beta$ & $B(S E)$ & $\beta$ \\
\hline T1 CES-D & $.56(.04)^{* * * *}$ & .56 & $.54(.05) * * *$ & .55 & $.54(.05)^{* * * * *}$ & .54 & $.54(.05)^{* * * * *}$ & .54 \\
\hline Gender & $.05(.05)$ & .05 & $.05(.05)$ & .04 & $.04(.05)$ & .03 & $.04(.05)$ & .03 \\
\hline Parental education & $-.00(.02)$ & -.01 & $.00(.02)$ & .00 & $.01(.02)$ & .02 & $.01(.02)$ & .02 \\
\hline African American & $.15(.08)$ & .09 & .14 (.09) & .08 & $.15(.08)$ & .09 & $.14(.09)$ & .09 \\
\hline Latino American & $-.05(.08)$ & -.04 & $-.06(.08)$ & -.04 & $-.05(.08)$ & -.04 & $-.06(.09)$ & -.04 \\
\hline Asian American & $-.07(.08)$ & -.06 & $-.08(.08)$ & -.06 & $-.05(.08)$ & -.04 & $-.05(.08)$ & -.04 \\
\hline Other ethnic groups & $.04(.07)$ & .03 & $.03(.07)$ & .02 & $.04(.07)$ & .03 & $.03(.07)$ & .03 \\
\hline Generational status & $-.01(.04)$ & -.02 & $-.01(.04)$ & -.02 & $-.01(.04)$ & -.01 & $-.01(.04)$ & -.01 \\
\hline $\mathrm{T} 1$ peer education & & & $-.02(.05)$ & -.02 & $-.01(.05)$ & -.01 & $-.01(.05)$ & -.01 \\
\hline $\mathrm{T} 1$ peer misconduct & & & $-.10(.10)$ & -.05 & $-.11(.11)$ & -.05 & $-.11(.11)$ & -.06 \\
\hline $\begin{array}{l}\text { T1 peer depressed } \\
\text { mood }\end{array}$ & & & $.07(.07)$ & .05 & $.04(.08)$ & .03 & $.04(.08)$ & .03 \\
\hline T1 VIP education & & & & & $-.05(.02)^{*}$ & -.11 & $-.05(.02)^{*}$ & -.11 \\
\hline T1 VIP misconduct & & & & & $.00(.17)$ & .00 & $.00(.17)$ & .00 \\
\hline $\begin{array}{l}\text { T1 VIP depressed } \\
\text { mood }\end{array}$ & & & & & $.12(.09)$ & .07 & (.09) & .07 \\
\hline Relationship length & & & & & & & $-.00(.01)$ & -.05 \\
\hline VIP is kin-related & & & & & & & $.06(.09)$ & .06 \\
\hline$\Delta R^{2}$ & & & .003 & & $.016^{*}$ & & .001 & \\
\hline$R^{2}$ & $.335^{* * * * *}$ & & $.338^{* * * *}$ & & $.354^{* * * * *}$ & & $.355^{* * * *}$ & \\
\hline $\operatorname{Adj} . R^{2}$ & $.320^{* * * * *}$ & & $.318^{* * * *}$ & & $.328^{* * * * *}$ & & $.325^{* * * * *}$ & \\
\hline
\end{tabular}

Note. CES-D $=$ Center for Epidemiologic Studies-Depression.

All predictors were centered and $n=361$.

$* p<.05 ; * * * * k<.001$.

school seniors whose VIP had higher educational attainment reported significantly less misconduct 1 year later. This association remained significant after considering kinship and length of relationship.

Depressive symptoms. Youth-reported depressive symptoms at T2 were regressed in the same four-step design as explained previously. The full model (Table 6, see Step 4) accounted for 33\% of the variance in depressive symptoms at $\mathrm{T} 2, F(16,344)=11.84, p<.001$. Background characteristicsmainly prior-year depressive symptomatology-explained $32 \%$ of the variance in $\mathrm{T} 2$ depressive symptoms. (As in the case of other outcomes, depressive symptoms were quite stable between T1 and T2; see Table 2.) The addition of peer social capital on Step 2 did not explain significant additional variance whereas the addition of VIP characteristics on Step 3 did increase the explained variance. High school seniors with a VIP of higher educational 
attainment reported fewer depressive symptoms 1 year after high school. This association remained significant even after kinship and length of relationship were considered.

Demographic differences in the relation between VIP educational attainment and youth outcomes. Five interactions (i.e., VIP educational attainment with three ethnic dummy variables, gender, and parental education) were tested for each of the four T2 youth outcomes. None were significant. Thus, the associations found between VIP's educational attainment and T2 outcomes held across youth from the various aforementioned demographic backgrounds.

\section{DISCUSSION}

This 1-year prospective longitudinal study investigated the role of important nonparental adults in youth's transition from high school to the next phase of development. Findings from previous cross-sectional studies (Chen et al., 2003; Greenberger et al., 1998) led us to predict that educational and social characteristics of youths' VIP before the transition from high school would be significantly associated with changes in youth's outcomes during the transition year and would be unique in their contributions to explaining outcomes when compared with youth's peers. Our results confirm that most VIP's social capital was significantly related to youth's outcomes (i.e., educational expectations, postsecondary school grades, misconduct, and depressive symptoms) and revealed the importance of VIP's educational attainment in particular. Having a VIP with more education was associated with positive changes for all four outcomes variables, over and above participants" initial levels of these "outcome" measures, their demographic attributes, and peer characteristics. These results emphasize the potential value of important non parental adults in the after high school transition and highlight the possibility that their educational background is a particularly influential source of social capital.

It is noteworthy that the type of VIP (kin vs. nonkin) and the length of the youth-VIP relationship generally did not moderate the associations between VIP's educational attainment and youth outcomes, pointing to the possibility that the effectiveness of VIP relationships may not depend upon these particular relationship characteristics. The only exception was a significant interaction between kin status and VIP's educational attainment in predicting youth's educational expectations: nonkin VIP's educational attainment was strongly associated with positive changes in youth's educational expectations, whereas the association for kin VIP was extremely small, although still statistically significant, perhaps due to the large sample size (see Figure 1). One interpretation of this interaction is that relationships with nonkin VIPs who have low educational attainment may put youth at risk for lower educational attainment. This finding may be an example of the potential 
negative influences of VIPs, but in this case it is limited to nonkin VIPs and to educational expectations only. Future research can shed light on this issue by exploring the content of communications between youth and their kin and nonkin VIP with specific focus on postsecondary educational planning.

The fact that length of relationship did not have any significant effects is consistent with the literature on outcomes of mentoring programs (Dubois et al., 2002), which may be encouraging to mentoring programs with few available mentors. The important adult's social capital (educational attainment in this study, other psychological characteristics in previous crosssectional research such as Chen et al., 2003; Greenberger et al., 1998) appear to trump the bonds of kinship and duration of relationship. Perhaps VIPs with higher educational attainment are more likely to encourage youth to focus on obtaining further education as they navigate the transition to adulthood. VIPs with higher educational attainment may also experience less stress in their lives, or manage their stress more effectively, which may enable them to make their world more accessible and inviting to the youth. In contrast, VIPs with lower levels of educational attainment may be more inclined to advise youth to enter the occupational world and start "making a living" than to advise them to extend their education and thus prolong their dependence on others. It is additionally possible that interactions with VIPs with higher educational levels are qualitatively different when compared with VIPs with lower levels of education, which in turn could be more beneficial to adjusting to the transition after high school. For example, VIPs with higher educational attainment may place greater importance on youths' identity development as they encourage youth to further their education.

Several methodological issues and limitations of the study require commentary.

Although the current study lends support to the idea that in naturally occurring relationships, a VIP may exert a socializing influence upon youth, we should not ignore the fact that youth exercise choice among potential VIP. For example, youth with certain characteristics (e.g., aspirations to rise above current life circumstances) may be attracted to a VIP with more education. Of course, processes of selection and causation may both be at work. Because all data regarding participants, their peers, and VIP were collected from youth self-report, the data are potentially vulnerable to response bias. However, this limitation cannot account for our results in their entirety. For example, VIP's educational attainment predicted differences in youth's outcomes whereas in all four cases, analogous peer variables did not. Nonetheless, in future studies, it would be desirable to obtain additional data about important nonparental adult and peer characteristics from other sources. Furthermore, due to the constraints of the larger project on which this study is based, we were unable to include youths' perceptions of their parents' misconduct and depressed mood, which would have permitted a 
comparison of peer, VIP, and parental influences on these transition outcomes. Future research should examine all three sets of influences.

Despite the limitations mentioned, this study is the first research on natural mentors to use a short-term prospective longitudinal design and a multiethnic community sample. Furthermore, the use of analogous measures for participants' perceptions of their VIP and peers, and the use of multiple developmental outcomes as indicators of youth's success in the post-high school transition, add new dimensions to research on this topic. We conclude that VIPs are likely to have developmental significance to youth in the transition to adulthood, and we argue that our findings suggest that they provide a unique source of social capital when compared with peers.

\section{ACKNOWLEDGMENTS}

Research reported in this article was supported by the Max-Planck Award for International Cooperation funded by the German Federal Ministry of Education and Research (BMBF), the School of Social Ecology, and the Department of Psychology and Social Behavior at the University of California, Irvine. The authors are indebted to Laura Gil-Trejo for her invaluable help with data collection and management. We also thank the numerous undergraduate research assistants who helped us with phone interviews and data entry.

\section{REFERENCES}

Aiken, L. S., \& West, S. G. (1991). Multiple regression: Testing and interpreting interactions. Thousand Oaks, CA: Sage.

Allen, T. D., Eby, L. T., \& Lentz, E. (2006). Mentorship behaviors and mentorship quality associated with formal mentoring programs: Closing the gap between research and practice. Journal of Applied Psychology, 91, 567-578.

Beam, M. R., Chen, C., \& Greenberger, E. (2002). The nature of adolescents' relationships with their "very important" non-parental adults. American Journal of Community Psychology, 30, 305-325.

Beam, M. R., Gil-Rivas, V., Greenberger, E., \& Chen, C. (2002). Adolescent problem behavior and depressed mood: Risk and protection within and across social contexts. Journal of Youth and Adolescence, 31, 343-357.

Blyth, D. A., Hill, J. P., \& Thiel, K. S. (1982). Early adolescents' significant others: Grade and gender differences in perceived relationships with familial and nonfamilial adults and young people. Journal of Youth and Adolescence, 11, 425-450.

Brown, B. B., Classen, D. R., \& Eicher, S. A. (1986). Perception of peer pressure, peer conformity dispositions, and self-reported behavior among adolescents. Developmental Psychology, 22, 723-742.

Chang, E. S., Chen, C., Greenberger, E., Dooley, D., \& Heckhausen, J. (2006). What do they want in life? The life goals of a multi-ethnic, multi-generational sample of high school seniors. Journal of Youth and Adolescence, 35, 321-332.

Chen, C., Greenberger, E., Farruggia, S., Bush, K., \& Dong, Q. (2003). Beyond parents and peers: The role of important non-parental adults (VIPs) in adolescent development in China and the United States. Psychology in the Schools, 40, 35-50. 
Chen, C., Greenberger, E., Lester, J., Dong, Q., \& Guo, M. (1998). A cross-cultural study of family and peer correlates of adolescent misconduct. Developmental Psychology, 34, 770-781.

Coleman, J. S. (1988). Social capital and the creation of human capital. American Journal of Sociology, 94, S95-S120.

Darling, N., Hamilton, S., Toyokawa, T., \& Matsuda, S. (2002). Naturally occurring mentoring in Japan and the United States: Social roles and correlates. American Journal of Community Psychology, 30, 245-270.

Dubois, D. L., Holloway, B. E., Valentine, J. C., \& Cooper H, . (2002). Effectiveness of mentoring programs for youth: A meta-analytic review. American Journal of Community Psychology, 30, 157-197.

DuBois, D. L., \& Karcher, M. J. (2005). Youth mentoring: Theory, research, and practice. In D. L. DuBois \& M. J. Karcher (Eds.), Handbook of youth mentoring (pp. 2-11). Thousand Oaks, CA: Sage Publications Ltd.

DuBois, D. L., \& Silverthorn, N. (2005). Natural mentoring relationships and adolescent health: Evidence from a national study. American Journal of Public Health, 95, 518-524.

Farruggia, S., Greenberger, E., Chen, C., \& Heckhausen, J. (2006). Perceived social environment and adolescent well-being and adjustment: Comparing a foster care sample with a matched sample. Journal of Youth and Adolescence, 35, 349-358.

Garmezy, N. (1991). Resilience and vulnerability to adverse developmental outcomes associated with poverty. American Behavioral Scientist, 34, 416-430.

Greenberger, E., Chen, C., \& Beam, M. R. (1998). The role of "very important" non-parental adults in adolescent development. Journal of Youth and Adolescence, 27, 321-343.

Holmbeck, G. N. (2002). Post-hoc probing of significant moderational and mediational effects in studies of pediatric populations. Journal of Pediatric Psychology, 27, 87-96.

Kessler, R. C., Foster, C., Webster, P. S., \& House, J. S. (1992). The relationship between age and depressive symptoms in two national surveys. Psychology and Aging, 7, 119-126.

Klaw, E. L., Rhodes, J. E., \& Fitzgerald, L. F. (2003). Natural mentors in the lives of African American adolescent mothers: Tracking relationships over time. Journal of Youth and Adolescence, 32, 223-232.

Klaw, R. C., \& Rhodes, J. E. (1995). Mentor relationships and the career development of pregnant and parenting African-American teenagers. Psychology of Women Quarterly, 19, 551-562.

Levinson, D. J. (1978). The seasons of a man's life. New York, NY: Ballantine Books.

Moffitt, T. E., Caspi, A., Harrington, H., \& Milne, B. J. (2002). Males on the life-course-persistent and adolescence-limited antisocial pathways: Follow-up at age 26 years. Development and Psychopathology, 14, 179-207.

Radloff, L. (1977). The CES-D scale: A self-report depression scale for research in the general population. Applied Psychological Measurement, 1, 385-401.

Rhodes, J. E., Ebert, L., \& Fischer, K. (1992). Natural mentors: An overlooked resource in the social networks of young, African American mothers. American Journal of Community Psychology, 20, 445-461.

Rhodes, J., Spencer, R., Keller, T., \& Liang, B. (2006). A model for the influence of mentoring relationships on youth development. Journal of Community Psychology, 34, 691-701.

Werner, E. E., \& Smith, S. (1977). Kauai's children come of age. Honolulu, HI: University of Hawaii Press.

Werner, E. E., \& Smith, S. (1982). Vulnerable but not invincible: A study of resilient children. New York, NY: McGraw Hill.

Zimmerman, M. A., Bingenheimer, J. B., \& Notaro, P. C. (2002). Natural mentors and adolescent resiliency: A study with urban youth. American Journal of Community Psychology, 30, 221-243. 